2016

\title{
Appearance of Membrane Compromised, Viable But Not Culturable and Culturable Rhizobial Cells as a Consequence of Desiccation
}

Jan A.C. Vriezen

Smith College,jvriezen@smith.edu

Frans J. de Bruijn

Michigan State University

Follow this and additional works at: https://scholarworks.smith.edu/bio_facpubs

Part of the Biology Commons

\section{Recommended Citation}

Vriezen, Jan A.C. and de Bruijn, Frans J., "Appearance of Membrane Compromised, Viable But Not Culturable and Culturable Rhizobial Cells as a Consequence of Desiccation" (2016). Biological Sciences: Faculty Publications, Smith College, Northampton, MA.

https://scholarworks.smith.edu/bio_facpubs/54 
1 Appearance of Membrane Compromised, Viable But Not Culturable

2 and Culturable Rhizobial cells as a consequence of Desiccation.

4 J.A.C. Vriezen ${ }^{1}$ and F.J. de Bruijn ${ }^{2}$

$6{ }^{1}$ Department of Biological Sciences, Clark Science Center, 44

7 College Lane, Smith College, Northampton, MA. 'INRA-CNRS,

8 Laboratoire des Interaction Plantes Micro-organismes (LIPM), 24

9 Chemin de Borde Rouge, Auzeville CS52627, Castanet Tolosan,

10 CEDEX, France.

11

12 Number of words: 8769

13 Number of tables: 1

14 Number of figures: 4

15

$16{ }^{1}$ Corresponding author: J.A.C. Vriezen

17 Email: jvriezen@smith.edu, Telephone:(413) 585 7594, Fax: (413)

$18 \quad 585 \quad 4534$

19

$20{ }^{1}$ Present address: Department of Biological Sciences, 44 College

21 Lane, Smith College, Northampton, MA 01063

22

23 Running title: Different fractions of cells after desiccation 
25 Keywords: Desiccation, Viable but not Culturable, VBNC,

26 Sinorhizobium, smc01590

27

28

29

30

31

32

33

34

35

36

37

38

39

40

41

42

43

44

45

46

47

48 


\section{Abstract}

50 For agricultural purposes, drought related stresses negatively

51 affect the Rhizobiaceae in at least three ways. Firstly,

52 rhizobial populations are affected by desertification of

53 agricultural soils. Secondly, the quality of dry-base inocula,

54 also called formula, is negatively affected by a drying step,

55 and thirdly, rhizosphere bacteria protect crop-plants against

56 drought. Although survival of cultivatable bacteria has been

57 studied intensively in dry-base seed inocula and in-vitro, thus

58 far research has only marginally addressed the bacterial cell,

59 its cellular structures and physiology. Many questions remain

60 regarding the sensing of and physiological response of rhizobia

61 to desiccation. This review will focus on the three different

62 fractions of cells after desiccation, the membrane compromised

63 cells, the viable but not culturable cells and the culturable

64 cells.

65

66

67

68

69

70

71

72 


\section{Introduction and Discussion}

74 According to Veron et al. [2006], 40\% of the world's surface is

75 threatened by desertification related problems, and consequently

76 the degradation of soil quality due to drought and salinity.

77 Drought and salinity are considered the most important abiotic

78 stresses in many areas in the world, and it is estimated that 1

79 billion people worldwide populate these lands. Of particular

80 importance to the agricultural industry is the impact of these

81 harsh environmental conditions on the soil-borne endogenous

82 group of proteobacteria, the rhizobia [Zahran, 1999; Fierer et

83 al., 2003; Griffiths et al., 2003; Dardanelli et al., 2012).

84 The Rhizobiaceae is a bacterial family of enormous

85 agricultural importance due to their ability to fix atmospheric

86 nitrogen in an intimate relationship with plants in root or stem

87 nodules enhancing growth under nitrogen limiting conditions.

88 This relationship is negatively impacted by drought related

89 stresses [Jones et al., 2009; Zahran, 1999]. In addition, these

90 bacteria can also improve drought tolerance of agricultural

91 crops [Grover et al., 2011; Zahran, 2010; Dodd and Perez-

92 Alfocea, 2012; Bianco and Defez, 2009]. To make optimal use of

93 the process of nitrogen fixation, seed inoculation companies

94 apply Rhizobium strains to the seed surface that are selected

95 for their ability to efficiently colonize the rhizosphere and

96 fix nitrogen. Unfortunately, many inoculants remain unreliable 
97 because of the inability of bacterial cells to persist under

98 adverse conditions, negatively affecting colony-forming units

99 (CFU) of added rhizobia [Kosanke et al., 1992; Deaker et al.,

100 2004; Catroux et al., 2001; Smith, 1992; Bullard et al., 2004;

101 Herridge, 2007]. Furthermore, Ilyas and Bano [2012] provided a

102 nine-point list of characteristics that Plant Growth Promoting

103 Rhizobacteria [PGPR] should have for successful dry-base

104 formulation development. This list includes desiccation

105 resistance.

106 The ability of selected strains to survive desiccation

107 depends on many factors, for example, the drying method used,

108 such as forced-drying using vacuum versus air-drying, the media

109 used, the speed and severity of drying, the extent and speed of

110 rehydration, the growth-phase, the drying temperature, the

111 availability of solutes and the carrier material [Vriezen et

112 al., 2006; 2007]. In addition, intragenic differences to cope

113 with desiccation stress affect survival. For example, slow

114 growers tend to be more desiccation resistant than fast-growers

115 [Zahran, 2001]. These data suggest that no single trait affects

116 the ability of rhizobia to survive desiccation but that several

117 mechanisms are likely responsible [Vriezen et al., 2006; 2007;

118 2013].

119 In a review by Vriezen et al. [2007], the authors provided 120 a hypothetical model for the response of rhizobia to desiccation 
121 (Figure 1). The model includes two not mutually exclusive

122 physiological responses. Upon drying, rhizobia sense the

123 consequences of drying, which may be the lowering of

124 wateractivity $\left(\mathrm{A}_{\mathrm{w}}\right)$, accumulation of solutes and concentration of

125 enzymes. Thus far it remains unclear how desiccation is sensed

126 and resistance is mediated [Vriezen et al., 2005; 2007; Hirsh,

127 2010). The response likely includes the accumulation of

128 osmoprotectants and compatible solutes known to increase

129 desiccation survival. For example, trehalose increases the

130 ability to survive desiccation [McIntyre et al., 2007]. Also

131 heat shock protein (HSP) and chaperones and reactive oxygen

132 species (ROS) scavenging enzymes accumulate [Feng et al., 2002;

133 Cytryn et al., 2007]. In contrast, when cells are desiccated,

134 cells are not active, thus damage accumulates due to the

135 inability to repair those. Consequently, upon rewetting and

136 regaining of metabolism cells get the opportunity to repair

137 damage accumulated during storage or that acutely appears upon

138 rewetting. These damages include damage to DNA, damage to

139 membranes and the cell wall [Humann et al., 2009; Potts, 1994;

140 Leslie et al., 1995; Vriezen et al., 2012; Salema et al., 1982;

141 Bushby and Marshall, 1977B].

142

143 Figure 1: Model representing two hypothetical pathways for

144 responses of rhizobia to desiccation stress and desiccation- 
145 induced damages.

146

147 Although improvement of long-term survival and seed inocula

148 storage time has been the focus of desiccation research,

149 relatively little work has focused primarily on the bacterial

150 cell. Most, if not all, research only used culturability as a

151 measure to estimate survival consequently marginalizing often

152 the vast majority of cells not forming colonies. But what is the

153 fate of the cells not forming colonies? Recently, Vriezen et al.

154 [2012] described the appearance of Viable But Not-Culturable

155 (VBNC) Sinorhizobium meliloti cells upon desiccation and

156 resuscitation. Because a major target for desiccation stress are

157 the cell membranes, they hypothesized that cells, which lost the 158 ability to form colonies, have compromised cell membranes

159 [Potts, 1994; Leslie et al., 1995]. Thus, it was expected that

160 all cells not forming colonies were membrane compromised. To

161 test this, Vriezen et al. [2012] applied the live/dead stain to

162 cells after desiccation. This stain uses two dyes, syto-9 and

163 propidium iodide, which differ in their ability to cross the

164 cytoplasmic membrane. Syto-9 can always cross the membrane and

165 stains all cells green. However, propidium iodide can only cross

166 the membrane when the permeability is increased and staining the

167 cell red. These red cells are dead. When this stain was used on

168 rhizobial cells prior to and after drying, unexpected results 
169 were obtained. The data presented in figure 2 shows that two

170 staining methods (crystal violet and live/dead) yielded the same

171 results prior to drying, after three days at $100 \% \mathrm{RH}$ and after

172 three days at 22\% RH. The increase in countable cells at $100 \% \mathrm{RH}$

173 conforms to what one expects since an increase in colony forming

174 units was observed over three days at 100\% RH in previous

175 studies [Vriezen et al., 2006]. However, a change in the

176 fraction of red (dead) and green (living cells) was observed.

177 Prior to drying, the red fraction of cells was very low

178 (4.4+0.5\%) and increased substantially during desiccation to

$17956.9+10.6 \%$. During this process, culturability decreased to

$1803.1 \%$. If it is assumed that the colony forming cells are a

181 fraction of the viable cells, we can only conclude that many

182 cells are alive but are not able to form colonies and are in a

183 VBNC state. This VBNC state exists in many microorganisms,

184 including rhizobia [Manahan and Steck, 1997; Alexander et al.,

185 1999; Basaglia et al., 2007; Räsänen et al., 2001; Vriezen et

186 al., 2012; Catroux et al., 2001]. The induction of this

187 physiological state by desiccation is a novel and very relevant

188 observation since only cells able to form colonies can infect

189 plants, as reported for strain S. meliloti 41 [Basaglia et al.,

190 2007]. The term VBNC applies directly to the observations

191 presented in Figure 2: Cells of Sinorhizobium meliloti 1021,

192 that were rehydrated after desiccation, can be divided into 
193 three different fractions of cells after desiccation, the

194 membrane compromised- $(\mathrm{MC})$, the viable but not culturable-

195 (VBNC), and the culturable cells (colony forming units, or CFU)

196 and correspond to fraction III, II and I in Vriezen et al.

197 [2012] respectively.

198

199 Figure 2: Survival and recovery of S. meliloti cells after

200 drying and rewetting.

201

202 The Membrane Compromised (MC) fraction

203 Fraction III: That cell membranes are a target for desiccation

204 is not novel, however, the extent to which desiccation

205 compromises membranes in Sinorhizobium meliloti 1021 is

206 unexpected. In the aforementioned study, 56.9+10.6\% of cells

207 stain red and have lost membrane integrity, indicating that of

208 the very substantial number of cells not forming colonies (100\%-

$2093.1 \%=96.9 \%)$, 59\% of this fraction have non-functional membranes.

210 Thus, the loss of membrane integrity is the main cause of death

211 for Sinorhizobium meliloti 1021. Vriezen et al. [2012]

212 hypothesized that this desiccation-induced loss of membrane

213 integrity can be explained by changes in phase transition of

214 phospholipid membranes, due to the removal of water affecting

215 the phospholipid head spacing and due to rehydration and the

216 consequent breakage of the cell wall. Furthermore, lipid 
217 peroxidation and $\mathrm{Fe}^{3+}$ catalyzed oxidation also lead to the loss

218 of structure of the membranes when cells are not able to repair

219 damages [Deaker et al., 2004; Potts, 1994]. Under normal wetted

220 conditions, membranes are in the liquid crystalline phase

221 (Figure 3A). Upon the extraction of water, phase transition

222 occurs leading to the gel-phase of the membrane. Upon rewetting,

223 phase transition occurs again, leading to leakage of cell

224 constituents from the cell and to the loss of membrane integrity

225 and cell death.

226 Phase transition can be followed using Fourier

227 Transformation Infra Red [FTIR, Leslie et al., 1995]

228 spectroscopy in which the vibration frequency of the

229 phospholipid head groups is measured (Figure 3B). Upon

230 decreasing temperatures, this frequency decreases indicating

231 membrane transition. The temperature at which this transition

232 occurs is the midpoint temperature. Interestingly, if ambient

233 temperature is higher than the membrane midpoint temperature, no

234 phase transition occurs upon drying and rewetting, reducing cell

235 death. However, when drying takes place at an ambient

236 temperature below the midpoint temperature, cell death due to

237 membrane transition is increased. A consequence of a change in

238 membrane midpoint temperature can be seen in the change in

239 vibration frequency (Figure 3B). When the midpoint temperature

240 is lowered one expects the temperature at which phase transition 
241 occurs to be lower resulting in a wider window of ambient

242 temperatures higher then the midpoint temperature, increasing

243 survival. Survival data indicates that this is what happens

244 after desiccation of Sinorhizobium meliloti 1021. An increase in

245 viability was observed with increasing temperature with a

246 maximum at $37^{\circ} \mathrm{C}$ indicating that this process may underlie the

247 observations [Vriezen et al., 2006].

248

249 Figure 3: Membrane properties.

250

25

The structural adaptations to membrane phospholipids that

252 affect fluidity and midpoint temperature are the following: Non-

253 reducing sugars such as trehalose stabilize the phospholipid

254 head spacing of the membranes, leading to a decrease of the

255 membrane midpoint temperature and increased survival even at

256 lower ambient temperature (Figure 3A\&B). Also longer fatty acids

257 decrease fluidity leading to an increase in the midpoint

258 temperature. Furthermore, an increase in cis-bonding, thus an

259 increase in unsaturation leads to an increased fluidity, thus a

260 lower midpoint temperature [Leslie et al., 1995]. Therefore, a

261 decrease in the unsaturated/saturated (u/s) ratio of membrane

262 phospholipids leads to a lower fluidity and a higher midpoint

263 temperature. Boumahdi et al. [1999] studied survival after

264 desiccation of S. meliloti, B. japonicum and B. elkanii in 
265 relation to growth-phase and the fatty acid u/s ratio. Even

266 though differences in $\mathrm{u} / \mathrm{s}$ were found depending on the growth-

267 phase, these differences did not correlate with the ability to

268 survive desiccation at many $\mathrm{RH}^{\prime} \mathrm{S}(3-83.5 \% \mathrm{RH})$ except under the

269 following conditions: In B. elkanii, an increase in saturation

270 lead to a decrease in desiccation survival at $67.8 \% \mathrm{RH}$ at $30^{\circ} \mathrm{C}$,

271 and in B. japonicum, the same was seen at 3\% and 22\%RH. While

272 the expected correlations were seen in Bradyrhizobia under

273 certain conditions, this was not seen in S. meliloti RCR2011. In

274 another publication by Boumahdi et al. [2001], growth at

275 decreased water activities $\left(A_{w}\right)$ affected the u/s ratio in $S$.

276 meliloti 2011, B. elkanii and B. japonicum. This effect was

277 strongest in $B$. elkanii. Surprisingly though, with decreasing $A_{w}$

278 a decrease in u/s ratio was found, counter intuitive to what one

279 would expect in order to survive water-stress with the membrane

280 as major target. Why these correlations were not observed across

281 the range of $\mathrm{A}_{\mathrm{w}}{ }^{\prime} \mathrm{s}, \mathrm{RH}^{\prime} \mathrm{s}$, strains and growth-phases tested is

282 unclear. However, it indicates that other mechanism underlie

283 these phenomena.

284 In addition to the responses described above,

285 hypothetically, an increase in the concentration of hopanoids

286 should increase fluidity and lower the midpoint temperature.

287 Hopanoids are the prokaryotic equivalent of cholesterol in

288 eukaryotes [Kannenberg et al., 1999; Kannenberg et al., 1995]. 
289 Their function remains unknown, however, their presence in

290 membranes leads to reduced permeability and increased order of

291 membranes above the midpoint temperature at which molecular

292 disorder threatens membrane stability. These aliphatic compounds

293 have also been identified in Rhizobium but to our knowledge have

294 not yet been studied in relation to desiccation survival.

295

296 The Viable But Non-Culturable (VBNC) fraction

297 Fraction II: The second most important fraction in a culture of

298 cells after desiccation are the VBNC cells. Many environmental

299 factors have been identified inducing a VBNC state in bacteria,

300 such as temperature stress, osmotic upshift and oxygen stress,

301 tap water and the VBNC inducing component copper in $A$.

302 tumefaciens and R. leguminosarum [Oliver, 2005; Räsänen et al.,

303 2001; Manahan and Steck, 1997; Alexander et al., 1999]. Also

304 desiccation can induce a VBNC state in E. cloacae and $S$.

305 meliloti [Pederson and Jacobsen, 1993; Vriezen et al., 2012].

306 This VBNC fraction can be divided into two sub fractions, those

307 cells for which VBNC is reversible and can be resuscitated

308 (temporarily non-culturable), and those for whom VBNC is a

309 permanent state (permanently non-culturable) (Maraha, 2007). In

310 a paper by Hammes et al. [2011], the authors named these two

311 fractions "Potentially reversible, starved or injured" and

312 "Irreversible, or dying/dead". The demarcation of these two 
313 fractions is a hard to assess amount of DNA- and protein-

314 damage. It remains unclear which level of damage leads to death

315 or the inability to resuscitate.

316 Several researchers have attempted to understand the

317 conditions modulating the culturability of bacteria. Barry et

318 al. [1956] noted that autoclaving media leads to an increase in

$319 \mathrm{H}_{2} \mathrm{O}_{2}$ decreasing $\mathrm{CFU}^{\prime} \mathrm{S}$. The addition of sodium pyruvate and

320 catalase to the medium can increase resuscitation in many

321 organisms [Mizunoe et al. 1999; Imazaki and Nakaho, 2009].

322 However, this approach proved unsuccessful in S. meliloti 1021

323 and 41 [Basaglia et al., 2007; Vriezen et al., 2012]. It appears

324 that all desiccation and $\mathrm{O}_{2}$ limitation induced VBNC cells are in

325 a permanent state of non-culturability under the conditions

326 tested [Basaglia et al., 2007; Toffanin et al., 2000]. In

327 contrast, a very slow supply of oxygen appeared to resuscitate

328 some cells [Basaglia et al., 2007]. These results indicate that

329 resuscitation from the VBNC state differs between E. coli and

330 Rhizobium, even though $\mathrm{O}_{2}$ damage may occur in both cases.

331 One explanation for the occurrence of desiccation induced

332 rhizobial VBNC cells is that these cells are without a

333 functional template for the replication of DNA but have intact

334 membranes. DNA is a major target of desiccation in

335 microorganisms inducing double strand breaks in E.coli and D.

336 radiodurans [Asada et al., 1979; Mattimore and Battista, 1996]. 
337 In support of this hypothesis are the observations by Humann et

338 al. [2009], whom isolated a desiccation sensitive Sinorhizobium

339 mutant with a Tn5 insertion in its uvrC locus which is involved

340 in DNA repair. Therefore, the inability to repair desiccation

341 induced DNA damage leads to a decrease in CFU's and likely to an

342 increase in VBNC cells in rhizobia.

343 To identify additional physiological responses potentially

344 involved in the VBNC state of rhizobia, we consulted three

345 studies addressing the physiological responses of the VBNC state

346 in Pseudomonas and E. coli, both proteobacteria. The proteins

347 identified in these three studies are summarized in Table 1

348 [Maraha, 2007; Asakura et al., 2008; Muela et al., 2008].

349 Several loci, OmpW, HisJ and Prox were found in both

350 proteobacteria in more than one study. Surprisingly, OmpW, found

351 strongly expressed in VBNC cells in several microorganisms and

352 studies, could not be identified in s. meliloti. Actually, only

353 HisJ has significant identity in S. meliloti 1021 (>95\% of the

354 query sequence, and $>30 \%$ Identity). Using the same criteria,

355 five more loci were identified and are DdpA, TpiA, LeuD, OppA,

356 and EF-TU, which, together with HisJ are the first set of $S$.

357 meliloti candidate loci affecting the VBNC state. Interestingly,

358 neither the loci identified by Humann et al. [2009], nor those

359 involved in trehalose metabolism [Reina-Bueno et al., 2012;

360 McIntyre et al., 2007; Flechard et al., 2010], nor loci 
361 responsive upon desiccation [Cytryn et al., 2007] were

362 identified, indicating that DdpA, TpiA, LeuD, OppA, and EF-TU

363 represent a novel set of candidate loci for the rhizobial VBNC

364 state.

365

366 Table 1: Candidate loci in S. meliloti 1021 potentially involved

367 in the VBNC state.

368

369 How do these observations relate to Rhizobia?

370 Identification of the proteins mentioned above indicates that

371 damage to amino acid metabolism and protein synthesis, which may

372 result in permanent VBNC cells in Rhizobium. For example,

373 Asakura et al. [2008] showed that HisJ, LeuD and OppA were

374 increased in a oxidative- and osmo tolerant E. coli strain,

375 while TpiA was decreased compared to a oxidative- and osmo

376 sensitive E.coli strain after passing through the GI track. This

377 would indicate that strains not sensitive to oxygenic stress,

378 thus "VBNC resistant", have increased expression of HisJ, LeuD

379 and OppA. In Muela et al. [2008], EF-TU (TufA, involved in

380 recruiting charged tRNA to the a-site on the rhibosome) was

381 found expressed in the VBNC state in phosphate buffered saline

$382(\mathrm{PBS})$. According to Barcina and Arana [2008], this conforms to

383 the findings by Kong et al. [2004] in Vibrio vulnificus and

384 Asakura et al. [2007] in E. coli. Hydrogen peroxide sensitive 
385 Vibrio cells, having lost catalase activity, are entering the

386 VBNC state and have increased OmpW and TufA levels.

387 The hypothesis stated above is further supported by the

388 identification of relA mutants with a desiccation sensitive

389 phenotype by Humann et al., [2009]. RelA (stringent response) is

390 stimulated by aminotriazole (AT), a histidine analog inducing

391 histidine starvation [Wells and Long, 2002; Kroll and Becker,

392 2011]. Histidine starvation induces relA and therefore the

393 stringent response. HisJ mutants potentially induce histidine

394 starvation, thus these findings support the hypothesis that VBNC

395 cells are affected in amino acid metabolism and translation. A

396 substantial part of the permanently non-culturable rhizobial

397 cells after desiccation may thus be irreversible VBNC, or

398 dying/dead due to substantial amounts of DNA and protein damage.

399

400 The Culturable Fraction (CFU)

401 Fraction 1: The CFU fraction is the smallest of the three

402 recognized fractions of rewetted Sinorhizobium meliloti 1021

403 after desiccation. This fraction is so small [3.1\%, Vriezen et

404 al., 2012] that it falls within the error of measurement of the

405 MC fraction (+10.6\%). Thus, even a doubling in the fraction of

406 culturable cells would not be reflected in a significant change

407 in dead and living cells. Even though, it is the culturable

408 fraction that counts in formulations of rhizobia since non- 
409 growing but living cells do not contribute to nodule formation

410 [Basaglia et al., 2007]. Therefore, understanding the conditions

411 and cellular responses increasing this fraction remain of

412 crucial importance. Even though no data exist on how osmotic

413 stress and temperature affect the appearance of VBNC and MC

414 fractions, more is known about these conditions in relation to

415 desiccation survival.

416

417 Effect of osmotic and salt stress

418 In a review by Vriezen et al. [2007], the authors hypothesized

419 about the effect of $\mathrm{NaCl}$ stress on the ability of $S$. meliloti to

420 survive desiccation. Exposure to NaCl during drying may increase

421 the ability to survive desiccation even considering that salt

422 stresses, osmotic stresses and desiccation stress are very

423 different in essence. Osmotic stress is the abundance of

424 solutes, salt stresses, and of (non-) toxic ionic compounds,

425 while desiccation stress results from the lack of water. The

426 reason for the hypothesis is the available data indicating an

427 overlap in response between the stresses reviewed by Vriezen et

428 al. [2007]. The conclusions were that (i) chloride stress

429 induces a response in combination with nutrients from the media

430 that lead to an increase in survival, (ii) the response is

431 strain specific and (iii) the increase in CFU during $\mathrm{NaCl}$

432 mediated desiccation is physiological in origin. Even though the 
433 response of $S$. meliloti to $\mathrm{NaCl}$ does increase CFU after

434 desiccation, it does only exclude some aforementioned stresses

435 from inducing these physiological responses. However, in their

436 review Vriezen et al. [2007] argued that screening for loci

437 responsive to $\mathrm{NaCl}$ stress would select for loci potentially

438 involved in survival during desiccation. In support of this are

439 the findings by streeter [2007] that NaCl increases

440 intracellular trehalose content in Bradyrhizobium japonicum, and

441 the finding by Humann et al. [2009], who showed that a rpoE2

442 mutant was sensitive to desiccation. RpoE2 is a response

443 regulator for envelop-stress. The hypothesis is further

444 supported with the identification of the s. meliloti 1021 mutant

445 with a Tn5luxAB transcriptional fusion inserted in a $\mathrm{NaCl}$

446 inducible putative Open Reading Frame (ORF, ngg) sensitive to

447 survival during desiccation [Vriezen et al., 2005; 2013]. Ngg is

448 responsive to $\mathrm{NaCl}$ stress and also affects the ability of $S$.

449 meliloti 1021 to survive desiccation.

450 Which $\mathrm{NaCl}$ mediated responses affect survival during

451 desiccation? We address four potential responses. Firstly,

452 although certain compatible solutes and osmoprotectants

453 accumulate during $\mathrm{NaCl}$ and osmotic stress and have a positive

454 effect on the survival during desiccation of Rhizobium, others

455 have not. For example, in rhizobia, the recently identified NaCl

456 induced loci asno and ngg involved in the production of the 
457 dipeptide NAGGN show differential responses to desiccation

458 [Vriezen et al. 2005; 2013; Sagot et al., 2010]. A Tn5luxAB

459 insertion in locus asno does not lead to a decrease in survival

460 during desiccation, while an insertion in locus ngg does. This

461 indicates that NAGGN accumulation as a response to NaCl stress,

462 does not affect the ability to survive desiccation since both

463 loci are involved in the synthesis of NAGGN. In contrast,

464 compatible solutes like sucrose and trehalose are known to

465 affect survival by their stabilizing abilities of the cell

466 membrane. Trehalose accumulates in osmo-stressed rhizobia and

467 provides protection against desiccation by maintaining membrane

468 integrity during drying and rewetting. Its presence may explain

469 the increase in desiccation survival during the stationary phase

470 and when rhizobial cells are exposed to NaCl [Welsh and Herbert,

471 1999; Breedveld et al., 1990; 1993; Streeter et al., 2003;

472 Leslie et al., 1995; Potts, 1994; Reina-Bueno et al., 2012;

473 McIntyre et al., 2007; Flechard et al., 2010]. Gouffi et al.

474 [1995; 1998; 1999; 2000] found that trehalose and sucrose are

475 synthesized de novo during exponential growth. Uptake mechanisms

476 in rhizobia were also described; an agl operon for

477 trehalose/maltose and sucrose uptake (smb03060-03065) was

478 identified by Willis and Walker [1999] and Jensen et al. [2002]

479 identified an alternative trehalose/maltose/sucrose operon (thu, 480 smb20324-20330). Dominique-Ferreras et al. [2006] showed that 
481 the thu operon is upregulated during an osmotic upshift and the

482 importance of the osmotic stress responsive loci otsA and tres

483 in trehalose accumulation. McIntyre et al. [2007] showed that

484 otsA provides resistance to desiccation. Interestingly,

485 trehalose synthesis genes (otsAB and tres) are increasingly

486 expressed during drying of Bradyrhizobium japonicum [Cytryn et

487 al., 2007] and Sugawara et al. [2010] shows that tres and trey

488 mutants of this organism have lower survival rates after

489 desiccation.

490 Wei et al. [2004] and Miller-Williams et al. [2006] also

491 identified Sinorhizobium mutants unable to grow at increased

492 NaCl concentrations. The mutations causing these phenotypes were

493 traced to genes involved in the central metabolism, such as

494 elongation factors, chaperones and cell division proteins. Also

495 genes for DNA ligases were higher expressed as well as a

496 putative DNA polymerase, an invertase and a ribonuclease. These

497 observations are most interesting considering VBNC cells may not

498 be able to resume growth after exposure to desiccation

499 conditions due to extensive DNA damage. If these responses

500 affect desiccation resistance or the appearance of desiccation

501 induced VBNC cells in Rhizobium remains to be seen.

502 Polysaccharides are of interest with respect to desiccation

503 since adaptations of the polysaccharide composition have been

504 observed for $S$. meliloti undergoing osmotic stress and are known 
505 to affect survival during dry conditions [Breedveld et al.,

506 1991; Llorett et al., 1998; Chenu, 1993]. Vanderlinden et al.

507 [2011] identified a $R$. Ieguminosarum Tn5 mutant in which

508 exopolysaccharide (EPS) production positively correlates with

509 desiccation resistance. The open reading frame mutated is

510 RL2975, however, a similar ORF does not exist in $S$. meliloti.

511 The mutant was not sensitive to hyperosmotic stress, nor

512 sensitive to detergents, suggesting the outer membrane was not

513 affected. However, it is nä̈ve to consider polysaccharides a

514 panacea to all desiccation related issues. Vriezen et al. [2007]

515 evaluated many reasons why this is not the case and gave

516 examples of studies resulting in contradictory observations. For

517 example, a decrease in survival of colony forming rhizobia was

518 observed upon the addition of polysaccharides when dried at a RH

$519>$ 3\%, but an increase in survival at 3\% relative humidity [Mary

520 et al., 1986]. Polysaccharide-producing variants of Rizobium

521 trifolii in sandy soil and under fast drying conditions showed

522 no consistent improvement in survival [Bushby et al., 1977A].

523 Osa-Afiana and Alexander [1982] showed that, when dried slowly

524 in Collamer silt loam, the production of EPS decreases survival

525 during desiccation of Bradyrhizobium japonicum strains, even

526 though polysaccharides did increase survival of $R$. trifolii 412

527 in a Lima silt loam [Pena-Cabrialis and Alexander, 1979]. The

528 reason for these apparent contradictions is likely due to the 
529 complexity of- and ambient conditions during- desiccation. A

530 polysaccharide may provide protection under one condition while

531 is detrimental under other conditions. The mechanisms by which

532 polysaccharides provide protection are not clear and specific

533 properties of polysaccharides have different effects on a

534 microorganism's ability to survive desiccation. Four of these

535 properties are (i) buffering against changes in water content,

536 (ii) exclusion of toxic compounds, such as $\mathrm{Cl}^{-}$and $\mathrm{O}_{2}$, (iii) the

537 final water content of polysaccharides under ambient conditions,

538 and (iv) the effect of hysteresis in the water retention

539 isoterms of polysaccharides [Potts, 1994; Rinaudo, 2004; Chenu,

$540 \quad 1993]$

541 Existing data on the environmental conditions affecting

542 polysaccharide production show that an increase in osmotic

543 pressure results in enhanced production of high molecular weight

544 (HMW) succinoglycan over low molecular weight (LMW)

545 succinoglycan [Breedveld et al., 1991] and that the expression

546 of genes involved in EPSI production are up-regulated during

547 salt stress [Ruberg et al., 2003, Jofre and Becker 2009]. These

548 observations suggest that in $S$. meliloti NaCl-dependent EPS

549 production leads to the production of HMW succinoglycan,

550 resulting in an increase in $\mathrm{CFU}^{\prime} \mathrm{s}$ after desiccation. In

551 addition, structural changes under the influence of osmotic- and

552 salt stress have also been reported for lipopolysaccharides 
553 (LPS) [Bhattacharya and Das, 2003; Llorett et al., 1995].

554 Interestingly, Llorett et al. [1995] found a different LPS

555 content in EFB1 cells grown on different salts, while

556 polyethylene glycol (PEG) 200, which causes only osmotic stress,

557 does not induce such a change. These differential responses may

558 correlate with the differences in survival during desiccation

559 when exposed to several different salts and argue for a

560 potential role of LPS in survival during desiccation [Vriezen et

561 al., 2006]. Indeed, Vanderlinden et al. (2010; 2011; 2012)

562 showed that a mutation in the fabFl and fabF2 gene in $R$.

563 leguminosarum, involved in LPS formation increased sensitivity

564 to desiccation and osmotic stress. Thus, structurally intact LPS

565 are important in protecting $R$. leguminosarum cells against

566 desiccation.

567 Vriezen et al. [2007] hypothesized that enzymes involved in

568 the production of HMW succinoglycan would positively affect

569 CFU's. For example, mutations in S. meliloti ExoP (Smb21506) was

570 found to block polymerization of EPS1, and ExoQ (Smb20944) is

571 required for the production of HMW succinoglycan [Gonzales et

572 al., 1998; Jofre and Becker, 2009]. In support of this

573 theoretical consideration was the $\sim 5$ fold induction of exoP in

574 desiccated Bradyrhizobium japonicum [Cytryn et al., 2007].

575 Interestingly, in S. meliloti depolymerization of HMW leads to

576 the production of LMW succinoglycan, which is ExoK (Smb20955) 
577 and ExsH (Smb20932) mediated [York and Walker, 1998]. However,

578 Cytryn et al. [2007] did not find these genes in their induction

579 studies.

580 Lastly, Cytryn et al. [2007] found an upregulation of

581 glycogen synthase (glgA) during desiccation. Glycogen may assist

582 in restoring cell volume after osmotic shock [Han et al., 2005].

583 The glgA2, glgB2 and glgX genes involved in glycogen metabolism

584 (smb20704, smb21447, smb21446 respectively), are higher

585 expressed during exposure to osmotic stress and may have a role

586 in desiccation survival.

587

588 The impact of temperature

589 Theoretically, temperature is involved in survival during

590 desiccation through the phase change of membranes during drying

591 and rewetting leading to the loss of membrane integrity (Leslie

592 et al., 1995). The logical consequences of this process would be

593 that an increase in drying temperature prevents membrane

594 transition. Vriezen et al. [2006] and this manuscript (Figure 4)

595 found a positive correlation between survival and temperature

596 with an optimum at $37^{\circ} \mathrm{C}$. This indicates a potential physiological

597 response to temperature affecting survival after desiccation.

598 Vriezen et al. [2007] reviewed the conditions in soil and

599 seed inocula and concluded they do not support the in vitro

600 observations, because many different researchers obtained 
601 contradictory results. They concluded that at least one

602 additional factor must exist applying an unknown, yet overruling

603 stress to dry cells. For example, (i) dry seed inocula have a

604 water activity of 0.45-0.6 thus still contain a relatively high

605 amount of water [Smith, 1992; Deaker et al., 2004]. (ii)

606 Isolated rhizobia show large differences in their ability to

607 respond- and adapt to life at high temperature which is not

608 necessarily linked to their ability to survive desiccation

609 [Trotman and Weaver, 1995]. Therefor, heat-tolerant strains may

610 not have an increased ability to survive desiccation, unless

611 temperature, rather than drought, is the superimposed stress.

612 However, the identification of a Azorhizobium sesbania Tn5

613 mutant sensitive to drought and temperature reveals a genetic

614 basis for this response in some strains [Rehman and Nautiyal,

615 2002]. In addition, Reina-Bueno et al. [2012] identified an otsA

616 mutant of $R$. etli which was affected by drying, but also lost

617 the response to temperature.

618 The molecular responses to stress in Rhizobia were recently

619 reviewed by Alexandre and Oliveira [2012] and include heat

620 inducible small heat shock proteins (HSP) [Ono et al. 2001;

621 Munchbach et al., 1999], the heat shock proteins DnakJ, GroESL

622 and GroEL [Minder et al. 1997; Rodrigues et al. 2006; Rodriquez-

623 Quinones, 2005; Fisher et al., 1993], transcriptional regulation

624 by RpoH (Narberhaus et al. 2005; Ono et al., 2001), and EPS and 
625 LPS [Nandal et al., 2005]. Potential sensing mechanisms involve

626 cis-acting ROSE elements or RNA thermometers [Waldminghaus et

627 al., 2005; Narberhaus et al. 2005; Nocker et al. 2001], and

628 thermo- induced changes in DNA structure and nucleoid associated

629 proteins [Shapiro and Cowen, 2012; Steinman and Dersch, 2013].

630 However, no papers were found on rhizobial thermosensing by

631 responding to changes in cell membranes.

632 Several of the aforementioned mechanisms may affect

633 survival of rhizobia after desiccation [Cytryn et al., 2007].

634 These authors showed an increase in expression of groEsL-related

635 chaperones, indicating a potential involvement of these genes in

636 survival during desiccation in Bradyrhizobium japonicum. It is

637 likely that similar mechanisms exist in Sinorhizobium meliloti.

638 Furthermore, Dominguez-Ferreras et al. [2006] identified several

639 loci responsive to an increase in osmotic and salinity stress

640 also associated with the temperature response. Most

641 interestingly, RpoE2 (Smc01506), affecting survival during

642 desiccation, also controls 44 genes involved in the heat-shock

643 response [Humann et al., 2009; Sauviac et al., 2007]. Therefore,

644 RpoE2 may regulate the part of the osmotic and temperature

645 response also affecting its ability to survive and grow after

646 desiccation.

647

648 
$649 \mathrm{NaCl}$ and temperature: An interconnected response to desiccation?

650 Intellectually it makes sense that microorganisms respond to an

651 increase of solutes or to temperature in order to respond to

652 desiccation. However, how likely is to have a molecular junction

653 of a NaCl inducible gene that, when knocked out, leads to

654 temperature dependent desiccation sensitivity? In addition to

655 some NaCl induced loci described earlier, locus smb01590, found

656 by Vriezen et al. [2013], also affects survival during

657 desiccation (Figure 4). Interestingly, the ability of the mutant

658 carrying a Tn5luxAB insertion in ORF smc01590 (Sce-1) to survive

659 desiccation is better, albeit not significant $(P=0.22)$, than

660 that of the reference strain at $4{ }^{\circ} \mathrm{C}$. While survival of the

661 reference strain increases with increasing temperature, survival

662 of Sce-1 is decreasing with increasing temperature leading to a

663 much better survival of the reference strain at $37^{\circ} \mathrm{C}$. There are

664 at least two different not mutually exclusive explanations for

665 the observation. Firstly, this observation suggests the

666 involvement of the membrane in this process, since the reference

667 strain does respond exactly as explained above: If ambient

668 temperature is higher than the membrane midpoint temperature, no

669 phase transition occurs, reducing cell death and increasing

670 culturability. When drying takes place at an ambient temperature

671 below the midpoint temperature, cell death due to membrane

672 transition is increased. 
674 Figure 4: Survival after desiccation of S. meliloti 1021 and

675 Sce-1.

676

677 In mutant Sce-1, it appears that the inability to correctly

678 adjust the membrane midpoint temperature at increased

679 temperature leads to the opposite effect. At $4{ }^{\circ} \mathrm{C}$, cell death in

680 the reference strain and the mutant strain is comparable. The

681 reference strain can respond to increases in temperature leading

682 to increased survival. At $4{ }^{\circ} \mathrm{C}$, both strains experience an ambient

683 temperature lower than the membrane midpoint temperature leading

684 to similar survival rates. However, at increased temperatures,

685 the reference strain experiences an ambient temperature

686 comparable or higher than the midpoint temperature, which

687 increases survival. Due to the inability to lower the midpoint

688 temperature, the Sce-1 mutant still experiences an ambient

689 temperature lower than the midpoint temperature, leading to a

690 reduced survival compared to the reference strain.

691 Alternatively, a defect in the temperature response in

692 strain Sce-1 potentially leads to reduced survival rate with

693 increasing temperature. The lack of the production of heat shock

694 proteins and chaperones may explain this phenomenon. The

695 postulated non-exclusivity of the two hypothetical explanations 
696 allows that one of the responses to $\mathrm{NaCl}$ is the decrease of the 697 midpoint temperature. Interestingly, prodomain analysis of the aminoacid sequence

699 indicates that Smc01590 encodes a 210AA peptide with a leader

700 peptide targeting the cytoplasmic membrane. Smc01590 also

701 contains an SH2/SH3 domain. SH3 domains are called Molecular

702 Velcro [Morton and Campbel, 1994] due to their ability to form

703 strong bonds with other proteins by targeting proline rich

704 areas, which are also found in the sequence. Its location and

705 these domain/motif interactions suggest that Smc01590 can form

706 membrane located proteinaceous structures stabilizing the

707 membrane. Prodomain also predicts several cytoplasmic kinase

708 sites, which are commonly involved in signal transduction

709 directly or indirectly involved in sensing- and maintaining

710 membrane stability. Thus, it appears that Smc01590 is

711 potentially a sensor in a signal transduction pathway, in which

712 changes in membrane fluidity due to temperature and osmotic

713 pressure lead to the expression of downstream loci involved in

714 the lowering of the membrane midpoint temperature. This protein

715 and its locus are not under RpoE2 control, and may be part of a 716 novel signaling network.

717

718

719 


\section{Acknowledgements}

721 Some newly presented data has originated at Umass-Amherst or at

722 DOE-PRL-MSU.

723

\section{References}

725 Alexander E, Pham D, Steck TR. 1999. The viable-but-

726 nonculturable condition is induced by copper in Agrobacterium

727 tumefaciens and Rhizobium leguminosarum. Appl. Environ.

728 Microbiol. 65:3754-6.

729 Alexandre A, Oliveira S. 2012. Response to temperature stress in

730 rhizobia. Crit. Rev. Microbiol. 7:1-10.

731 Asada S, Takano M, Shibasaki I. 1979. Deoxyribonucleic acid

732 strand breaks during drying of Escherichia coli on a hydrophobic

733 filter membrane. Appl. Environ. Microbiol. 37:266-273.

734 Asakura H, Kawamoto K, Haishima Y, Igimi S, Yamamoto S, Makino

735 S. 2008. Differential expression of the outer membrane protein $W$

736 (OmpW) stress response in enterohemorrhagic Escherichia coli

737 O157:H7 corresponds to the viable but non-culturable state. Res.

738 Microbiol. 159:709-717.

739 Barcina I, Arana I. 2009. The viable but nonculturable

740 phenotype: A crossroads in the life-cycle of non-differentiating

741 bacteria? Rev. Environ. Sci. Biotechnol. 8:245-255.

742 Barry V, Conalty M, Denneny JM, Winder F. 1956. Peroxide

743 formation in bacteriological media. Nature 178(4533):596-7. 
744 Basaglia M, Povolo S, Casella S. 2007. Resuscitation of viable

745 but not culturable Sinorhizobium meliloti 41 prp4-luc: effects

746 of oxygen and host plant. Curr. Microbiol. 54:167-74.

747 Bhattacharya I, Das HR. 2003. Cell surface characteristics of

748 two halotolerant strains of Sinorhizobium meliloti. Microbiol.

749 Res. 158:187-194.

750 Bianco C, Defez R. 2009. Medicago truncatula improves salt

751 tolerance when nodulated by an indole-3-acetic acid-

752 overproducing Sinorhizobium meliloti strain. J. Exp. Bot.

$75360: 3097-3107$

754 Boumahdi M, Mary P, Hornez JP. 1999. Influence of growth phases

755 and desiccation on the degrees of unsaturation of fatty acids

756 and the survival rates of rhizobia. J. Appl. Microbiol. 87:611-

75761.

758 Boumahdi M, Mary P, Hornez JP. 2001. Changes in fatty acid

759 composition and degree of unsaturation of (Brady) rhizobia as a

760 response to phases of growth, reduced water activities and mild

761 desiccation. Ant. v. Leeuwenhoek. 79:73-79.

762 Breedveld M, Zevenhuizen L, Zehnder A. 1990. Osmotically induced

763 oligo-and polysaccharide synthesis by Rhizobium meliloti SU-47.

764 J. Gen. Microbiol. 136:2511-2519.

765 Breedveld MW, Dijkema C, Zevenhuizen LP, Zehnder AJ. 1993.

766 Response of intracellular carbohydrates to a NaCl shock in

767 Rhizobium leguminosarum biovar trifolii TA-1 and Rhizobium 
768 meliloti SU-47. J. Gen. Microbiol. 139:3157-3163.

769 Bullard G, Roughley R, Pulsford D. 2005. The legume inoculant

770 industry and inoculant quality control in Australia: 1953-2003.

771 Anim. Prod. Sci. 45:127-140.

772 Bushby H, Marshall K. 1977A. Some factors affecting the survival

773 of root nodule bacteria on desiccation. Soil Biol. Biochem.

$7749: 143-147$.

775 Bushby H, Marshall K. 1977B. Desiccation induced damage to the

776 cell envelope of root nodule bacteria. Soil Biol. Biochem. 9:149 $777-152$.

778 Catroux G, Hartmann A, Revellin C. 2001. Trends in rhizobial

779 inoculant production and use. Plant and Soil. 230:21-30.

780 Chenu C. 1993. Clay- or sand-polysaccharide associations as

781 models for the interface between micro-organisms and soil: Water

782 related properties and microstructure. Geoderma. 56:143 - 156.

783 Cytryn EJ, Sangurdekar DP, Streeter JG, Franck WL, Chang W,

784 Stacey G, Emerich DW, Joshi T, Xu D, Sadowsky MJ. 2007.

785 Transcriptional and physiological responses of Bradyrhizobium

786 japonicum to desiccation-induced stress. J. bac. 189:6751-6762.

787 Dardanelli M, Medeot D, Paulucci N, Bueno M, Vicario J, Garcìa

788 M, Bensi N, Niebylski A. 2012. Biochemical processes of

789 rhizobacteria and their application in biotechnology. In: Malik

790 A, Grohmann E, editors. Environmental Protection Strategies for

791 Sustainable Development. The Netherlands: Springer. p. 379-396. 
792 Deaker R, Roughley RJ, Kennedy IR. 2004. Legume seed inoculation

793 technology-a review. Soil Biol. Biochem. 36:1275 - 1288.

794 Dodd IC, Pérez-Alfocea F. 201. Microbial amelioration of crop

795 salinity stress. J. Exp. Bot. 63:3415-3428.

796 Domìnguez-Ferreras A, Pérez-Arnedo R, Becker A, Olivares J, Soto

797 MJ, Sanjuán J. 2006. Transcriptome profiling reveals the

798 importance of plasmid psymB for osmoadaptation of Sinorhizobium

799 meliloti. J. bac. 188:7617-25.

800 Feng L, Roughley RJ, Copeland L. 2002. Morphological changes of

801 rhizobia in peat cultures. Appl. Environ. Microbiol. 68:1064-

$802 \quad 1070$.

803 Fierer N, Schimel JP, Holden PA. 2003. Influence of drying-

804 rewetting frequency on soil bacterial community structure.

805 Microb. Ecol. 45:63-71.

806 Fischer H, Babst M, Kaspar T, Acuna G, Arigoni F, Hennecke H.

807 1993. One member of a GroESL-like chaperonin multigene family in

808 Bradyrhizobium japonicum is co-regulated with symbiotic nitrogen

809 fixation genes. EMBO 12:2901-2912.

810 Flechard M, Fontenelle C, Blanco C, Goude R, Ermel G,

811 Trautwetter A. 2010. RpoE2 of Sinorhizobium meliloti is

812 necessary for trehalose synthesis and growth in hyperosmotic

813 media. Microbiol. 156:1708-1718.

814 González JE, Semino CE, Wang LX, Castellano-Torres LE, Walker

815 GC. 1998. Biosynthetic control of molecular weight in the 
816 polymerization of the octasaccharide subunits of succinoglycan,

817 a symbiotically important exopolysaccharide of Rhizobium

818 meliloti. PNAS. 95:13477-13482.

819 Gouffi K, Pichereau V, Rolland JP, Thomas D, Bernard T, Blanco

820 C. 1998. Sucrose is a nonaccumulated osmoprotectant in

821 Sinorhizobium meliloti. J. bac. 180:5044-5051.

822 Gouffi K, Pica N, Pichereau V, Blanco C. 1999. Disaccharides as

823 a new class of nonaccumulated osmoprotectants for Sinorhizobium

824 meliloti. Appl. Environ. Microbiol. 65:1491-1500.

825 Gouffi K, Bernard T, Blanco C. 2000. Osmoprotection by pipecolic

826 acid in Sinorhizobium meliloti: Specific effects of d and 1

827 isomers. Appl. Environ. Microbiol. 66:2358-2364.

828 Griffiths RI, Whiteley AS, O'Donnell AG, Bailey MJ. 2003.

829 Physiological and community responses of established grassland

830 bacterial populations to water stress. Appl. Environ. Microbiol.

$83169: 6961-6968$.

832 Grover M, Ali Sz, Sandhya V, Rasul A, Venkateswarlu B. 2011.

833 Role of microorganisms in adaptation of agriculture crops to

834 abiotic stresses. World J. Microbiol. Biotechnol. 27:1231-1240.

835 Hammes F, Berney M, Egli T. 2011. Cultivation-independent

836 assessment of bacterial viability. In: Müller S, Bley $T$,

837 editors. High Resolution Microbial Single Cell Analytics.

838 Berlin: Springer. p. 123-150.

839 Han Y, Zhou D, Pang X, Zhang L, Song Y, Tong Z, Bao J, Dai E, 
840 Wang J, Guo Z, et al. 2005. Comparative transcriptome analysis

841 of Yersinia pestis in response to hyperosmotic and high-salinity

842 stress. Res. Microbiol. 156:403-415.

843 Herridge D. 2007. Inoculation technology for legumes. In:

844 Dilworth MJ, James EK, Sprent JI, Newton WE, editors. Nitrogen-

845 fixing leguminous symbioses. The Netherlands: Springer. p. 77-

846115.

847 Hirsch AM. 2010. How rhizobia survive in the absence of a legume

848 host, a stressful world indeed. In: Seckbach J, Grube M,

849 editors. Symbioses and Stress. The Netherlands: Springer. p.

$850 \quad 375-391$

851 Humann JL, Ziemkiewicz HT, Yurgel SN, Kahn ML. 2009. Regulatory

852 and DNA repair genes contribute to the desiccation resistance of

853 Sinorhizobium meliloti 1021. Appl. Environ. Microbiol. 75:446-

85453.

855 Ilyas N, Bano A. 2012. Potential use of soil microbial community

856 in agriculture. In: Maheshwar DK, editor. Bacteria in

857 Agrobiology: Plant Probiotics. Berlin: Springer. p. 45-64.

858 Imazaki I, Nakaho K. 2009. Temperature-upshift-mediated revival

859 from the sodium-pyruvate-recoverable viable but nonculturable

860 state induced by low temperature in Ralstonia solanacearum:

861 Linear regression analysis. J. Gen. Plant Path. 75: 213-226.

862 Jensen JB, Peters NK, Bhuvaneswari TV. 2002. Redundancy in

863 periplasmic binding protein-dependent transport systems for 
864 trehalose, sucrose, and maltose in Sinorhizobium meliloti. J.

865 bac. $184: 2978-86$.

866 Jofré E, Becker A. 2009. Production of succinoglycan polymer in

867 Sinorhizobium meliloti is affected by smb21506 and requires the

868 n-terminal domain of ExoP. MPMI. 22:1656-1668.

869 Jones KM, Kobayashi H, Davies BW, Taga ME, Walker GC. 2007. How

870 rhizobial symbionts invade plants: The Sinorhizobium-Medicago

871 model. Nat. Rev. Microbiol. 5:619-33.

872 Kannenberg EL, Perzl M, Härtner T. 1995. The occurrence of

873 hopanoid lipids in Bradyrhizobium bacteria. FEMS Microbiol.

874 Lett. 127:255-262.

875 Kannenberg EL, Poralla K. 1999. Hopanoid biosynthesis and

876 function in bacteria. Naturwissenschaften. 86:168-176.

877 Kong I, Bates TC, Hülsmann A, Hassan H, Smith BE, Oliver JD.

878 2004. Role of catalase and OxyR in the viable but nonculturable

879 state of vibrio vulnificus. FEMS Microbiol. Ecol. 50:133-142.

880 Kosanke JW, Osburn RM, Shuppe GI, Smith RS. 1992. Slow

881 rehydration improves the recovery of dried bacterial

882 populations. Can. J. Microbiol. 38:520-525.

883 Krol E, Becker A. 2011. Ppgpp in Sinorhizobium meliloti:

884 Biosynthesis in response to sudden nutritional downshifts and 885 modulation of the transcriptome. Mol. Microbiol. 81:1233-1254. 886 Leslie SB, Israeli E, Lighthart B, Crowe JH, Crowe LM. 1995. 887 Trehalose and sucrose protect both membranes and proteins in 
888 intact bacteria during drying. Appl. Environ. Microbiol.

$88961: 3592-7$.

890 Lloret J, Bolanos L, Lucas MM, Peart JM, Brewin NJ, Bonilla I,

891 Rivilla R. 1995. Ionic stress and osmotic pressure induce

892 different alterations in the lipopolysaccharide of a Rhizobium

893 meliloti strain. Appl. Environ. Microbiol. 61:3701-3704.

894 Lloret J, Wulff BB, Rubio JM, Downie JA, Bonilla I, Rivilla R.

895 1998. Exopolysaccharide II production is regulated by salt in

896 the halotolerant strain Rhizobium meliloti EFB1. Appl. Environ.

897 Microbiol. 64:1024-1028.

898 Manahan SH, Steck TR. 1997. The viable but nonculturable state

899 in Agrobacterium tumefaciens and Rhizobium meliloti. FEMS

900 Microbiol. Ecol. 22:29-37.

901 Maraha N. 2007. Physiological status of bacteria used for

902 environmental applications. PhD thesis. Karolinska Institutet.

903 Stockholm.

904 Mary P, Ochin D, Tailliez R. 1986. Growth status of rhizobia in

905 relation to their tolerance to low water activities and

906 desiccation stresses. Soil Biol. Biochem. 18:179-184.

907 Mattimore V, Battista JR. 1996. Radioresistance of Deinococcus

908 radiodurans: functions necessary to survive ionizing radiation

909 are also necessary to survive prolonged desiccation. J. bac.

$910 \quad 178: 633-637$.

911 McIntyre HJ, Davies H, Hore TA, Miller SH, Dufour JP, Ronson CW. 
912 2007. Trehalose biosynthesis in Rhizobium leguminosarum bv.

913 trifolii and its role in desiccation tolerance. Appl. Environ.

914 Microbiol. 73:3984-3992.

915 Miller-Williams M, Loewen PC, Oresnik IJ. 2006. Isolation of

916 salt-sensitive mutants of Sinorhizobium meliloti strain Rm1021.

917 Microbiol. 152:2049-2059.

918 Minder A, Narberhaus F, Babst M, Hennecke H, Fischer HM. 1997.

919 The DnakJ operon belongs to the sigma32-dependent class of heat

920 shock genes in Bradyrhizobium japonicum. Mol. Gen. Genet. MGG.

$921254: 195-206$.

922 Mizunoe Y, Wai SN, Takade A, Yoshida S. 1999. Restoration of

923 culturability of starvation-stressed and low-temperature-

924 stressed Escherichia coli 0157 cells by using $\mathrm{H}_{2} \mathrm{O}_{2}$-degrading

925 compounds. Arch. Microbiol. 172:63-67.

926 Morton C, Campbell I. 1994. SH3 domains: Molecular 'Velcro'.

927 Curr. Biol. 4:615-617.

928 Muela A, Seco C, Camafeita E, Arana I, Orruno M, Lopez JA,

929 Barcina I. 2008. Changes in Escherichia coli outer membrane

930 subproteome under environmental conditions inducing the viable

931 but non culturable state. FEMS Microbiol. Ecol. 64:28-36.

932 Münchbach M, Nocker A, Narberhaus F. 1999. Multiple small heat

933 shock proteins in rhizobia. J. bac. 181:83-90.

934 Nandal K, Sehrawat AR, Yadav AS, Vashishat R, Boora K. 2005.

935 High temperature-induced changes in exopolysaccharides, 
936 lipopolysaccharides and protein profile of heat-resistant

937 mutants of Rhizobium sp. cajanus. Microbiol. Res. 160:367-373.

938 Narberhaus F, Waldminghaus T, Chowdhury S. 2006. RNA

939 thermometers. FEMS Microbiol. Rev. 30:3-16.

940 Nocker A, Krstulovic NP, Perret X, Narberhaus F. 2001. Rose

941 elements occur in disparate rhizobia and are functionally

942 interchangeable between species. Arch. Microbiol. 176:44-51.

943 Oliver J. 2005. The viable but nonculturable state in bacteria.

944 J. Microbiol. 43:93-100.

945 Ono Y, Mitsui H, Sato T, Minamisawa K. 2001 . Two RpoH homologs

946 responsible for the expression of heat shock protein genes in

947 Sinorhizobium meliloti. Mol. Gen. Genet. 264:902-912.

948 Osa-Afiana L, Alexander M. 1982. Differences among cowpea

949 rhizobia in tolerance to high temperature and desiccation in

950 soil. Appl. Environ. Microbiol. 43:435-439.

951 Pederson J, Jacobsen C. 1993. Fate of Enterobacter cloacae JP210

952 and AEO106 (pro101) in soil during waterstress: Effect on

953 culturability and viability. Appl. Environ. Microbiol. 59:1560-

9541564.

955 Pena-Cabriales J, Alexander M. 1979. Survival of Rhizobium in

956 soils undergoing drying. Soil Sci. Soc. Am. J. 43:962-966.

957 Potts M. 1994. Desiccation tolerance of prokaryotes. Microbiol.

958 Rev. 58:755-805.

959 Räsänen LA, Elväng AM, Jansson J, Lindström K. 2001. Effect of 
960 heat stress on cell activity and cell morphology of the tropical

961 Rhizobium, Sinorhizobium arboris. FEMS Microbiol. Ecol. 34:267-

962278.

963 Rehman A, Nautiyal CS. 2002. Effect of drought on the growth and

964 survival of the stress-tolerant bacterium Rhizobium sp. NBRI2505

965 sesbania and its drought-sensitive transposon Tn5 mutant. Curr.

966 Microbiol. 45:368-377.

967 Reina-Bueno M, Argandoña M, Nieto JJ, Hidalgo-Garcìa A,

968 Iglesias-Guerra F, Delgado MJ, Vargas C. 2012. Role of trehalose

969 in heat and desiccation tolerance in the soil bacterium

970 Rhizobium etli. BMC Microbiol. 12:207.

971 Rinaudo M. 2004. Role of substituents on the properties of some

972 polysaccharides. Biomacromol. 5:1155-1165.

973 Rodrigues CS, Laranjo M, Oliveira S. 2006. Effect of heat and pH

974 stress in the growth of chickpea mesorhizobia. Curr. Microbiol.

$975 \quad 53: 1-7$.

976 Rodrìguez-Quiñones F, Maguire M, Wallington E, Gould PS, Yerko

977 V, Downie J, Lund P. 2005. Two of the three GroEL homologues in

978 Rhizobium leguminosarum are dispensable for normal growth. Arch.

979 Microbiol. 183:253-265.

980 Rüberg S, Tian ZX, Krol E, Linke B, Meyer F, Wang Y, Pühler A,

981 Weidner S, Becker A. 2003. Construction and validation of a

982 Sinorhizobium meliloti whole genome DNA microarray: Genome-wide

983 profiling of osmoadaptive gene expression, J. Biotechnol. 
$984106: 255-268$.

985 Sagot B, Gaysinski M, Mehiri M, Guigonis JM, LeRudulier D,

986 Alloing G. 2010. Osmotically induced synthesis of the dipeptide

987 N-acetylglutaminylglutamine amide is mediated by a new pathway

988 conserved among bacteria. PNAS. $107(28)$ :12652-12657.

989 Salema M, Parker C, Kidby D, Chatel D, Armitage T. 1982. Rupture

990 of nodule bacteria on drying and rehydration. Soil Biol.

991 Biochem. 14:15-22.

992 Sauviac L, Philippe H, Phok K, Bruand C. 2007. An

993 extracytoplasmic function sigma factor acts as a general stress

994 response regulator in Sinorhizobium meliloti. J. Bac. 189:4204-

99516.

996 Shapiro RS, Cowen LE. 2012. Thermal control of microbial

997 development and virulence: Molecular mechanisms of microbial

998 temperature sensing. mBio. $3(5)$.

999 Smith R. 1992. Legume inoculant formulation and application.

1000 Can. J. Microbiol. 38:485-492.

1001 Steinmann R, Dersch P. 2013. Thermosensing to adjust bacterial

1002 virulence in a fluctuating environment. Fut. Microbiol. 8:85-

1003105.

1004 Streeter J. 2003. Effect of trehalose on survival of

1005 Bradyrhizobium japonicum during desiccation. J. Appl. Microbiol.

$100695: 484-491$.

1007 Sugawara M, Cytryn EJ, Sadowsky MJ. 2010. Functional role of 
1008 Bradyrhizobium japonicum trehalose biosynthesis and metabolism

1009 genes during physiological stress and nodulation, Appl. Environ.

1010 Microbiol. 76:1071-1081.

1011 Toffanin A, Basaglia M, Ciardi C, Vian P, Povolo S, Casella S.

1012 2000. Energy content decrease and viable-not-culturable status

1013 induced by oxygen limitation coupled to the presence of nitrogen

1014 oxides in Rhizobium hedysari. Biol. Fert. Soils. 31:484-488.

1015 Trotman AP, Weaver RW. 1995. Tolerance of clover rhizobia to

1016 heat and desiccation stresses in soil. Soil Sc. Soc. Am. J.

$101759: 466-470$.

1018 Vanderlinde EM, Harrison JJ, Muszyński A, Carlson RW, Turner RJ,

1019 Yost CK. 2010. Identification of a novel ABC transporter

1020 required for desiccation tolerance and biofilm formation in

1021 Rhizobium leguminosarum bv. viciae 3841. FEMS Microbial. Ecol.

$102271: 327-340$.

1023 Vanderlinde EM, Magnus SA, Tambalo DD, Koval SF, Yost CK. 2011.

1024 Mutation of a broadly conserved operon (rl3499-rl3502) from

1025 Rhizobium leguminosarum biovar viciae causes defects in cell

1026 morphology and envelope integrity. J. bac. 193:2684-2694.

1027 Vanderlinde EM, Yost CK. 2012 Genetic analysis reveals links

1028 between lipid a structure and expression of the outer membrane

1029 protein gene, RopB, in Rhizobium leguminosarum. FEMS Microbiol.

1030 Lett. 335:130-139.

1031 Verón SR, Paruelo JM, Oesterheld M. 2006. Assessing 
1032 desertification. J. Arid Environ. 66:751-763.

1033 Vriezen JAC. 2005. Responses of Sinorhizobium meliloti 1021 to

1034 water stress, PhD thesis. University of Massachusetts. Amherst.

1035 Vriezen JAC, de Bruijn FJ, Nüsslein KR. 2006. Desiccation

1036 responses and survival of Sinorhizobium meliloti USDA 1021 in

1037 relation to growth phase, temperature, chloride and sulfate

1038 availability. Lett. Appl. Microbiol. 42:172-178.

1039 Vriezen JAC, de Bruijn FJ, Nüsslein KR. 2007. Responses of

1040 rhizobia to desiccation in relation to osmotic stress, oxygen,

1041 and temperature. Appl. Environ. Microbiol. 73:3451-3459.

1042 Vriezen JAC, de Bruijn FJ, Nüsslein KR. 2012. Desiccation

1043 induces viable but non-culturable cells in Sinorhizobium

1044 meliloti 1021. AMB Express. 2:1-9.

1045 Vriezen JAC, de Bruijn FJ, Nusslein KR. 2013. Identification and

1046 characterization of a genetic locus involved in survival during

1047 desiccation of Sinorhizobium meliloti. Submitted to Appl.

1048 Environ. Microbiol.

1049 Waldminghaus T, Fippinger A, Alfsmann J, Narberhaus F. 2005. RNA

1050 thermometers are common in alpha and gamma proteobacteria. Biol.

1051 Chem. 386:1279-1286.

1052 Wei W, Jiang J, Li X, Wang L, Yang SS. 2004. Isolation of salt-

1053 sensitive mutants from Sinorhizobium meliloti and

1054 characterization of genes involved in salt tolerance. Lett.

1055 Appl. Microbiol. 39:278-283. 
1056 Wells DH, Long SR. 2002. The Sinorhizobium meliloti stringent

1057 response affects multiple aspects of symbiosis. Mol. Microbiol.

$1058 \quad 43: 1115-1127$.

1059 Welsh DT, Herbert RA. 1999. Osmotically induced intracellular

1060 trehalose, but not glycine betaine accumulation promotes

1061 desiccation tolerance in Escherichia coli. FEMS Microbiol. Lett.

$1062174: 57-63$.

1063 Welsh DT. 2000. Ecological significance of compatible solute

1064 accumulation by micro-organisms: From single cells to global

1065 climate. FEMS Microbiol. Rev. 24:263-290

1066 Willis LB, Walker GC. 1999. A novel Sinorhizobium meliloti

1067 operon encodes an alpha-glucosidase and a periplasmic-binding-

1068 protein-dependent transport system for alpha-glucosides. J. bac.

$1069181: 4176-4184$

1070 York GM, Walker GC. 1998. The Rhizobium meliloti ExoK and ExsH

1071 glycanases specifically depolymerize nascent succinoglycan

1072 chains. PNAS. 95:4912-4917.

1073 Zahran HH. 1999. Rhizobium-legume symbiosis and nitrogen

1074 fixation under severe conditions and in an arid climate.

1075 Microbiol. Mol. Biol. Rev. 63:968-89.

1076 Zahran HH. 2001. Rhizobia from wild legumes: diversity,

1077 taxonomy, ecology, nitrogen fixation and biotechnology. J.

1078 Biotechnol. 91:143-153.

1079 Zahran HH. 2010. Legumes-microbes interactions under stressed 
1080 environments. In: Khan MS, Musarrat J, Zaidi A, editors.

1081 Microbes for Legume Improvement. Vienna: Springer. p. 353-387.

1082

1083 


\section{Figure legends}

1085

1086 Figure 1

1087 Model representing two hypothetical pathways for responses of 1088 rhizobia to desiccation stress and desiccation-induced damages.

1089 The "preceding-storage induction" pathway (A) implies a response

1090 to water, osmotic, or salt stress, and the "post-storage

1091 induction" pathway (B) implies a response to the desiccation-

1092 induced damages upon rewetting. Reprinted with permission from

1093 Vriezen et al. [2007].

1094

1095 Figure 2

1096 Survival and recovery of $S$. meliloti cells after drying and

1097 rewetting. Quantitative recovery of cells (direct count) after

1098 three days of storage under 100\% or 22\% RH on nitrocellulose

1099 filters (white bar = cristal violet, light grey bar = Live/dead,

1100 dark grey bar = ored, black bar = ogreen). All error bars

1101 represent the SEM. Reprinted with permission from Vriezen et al.

$1102[2012]$.

1103

1104 Figure 3

1105 Membrane properties: (A) Phase transition from liquid

1106 crystalline to gel phase and the prevention by trehalose

1107 [amended from Welsh, 2000]. (B) Vibration frequencies of the 
1108 phosphate head-groups and the effect of trehalose on the

1109 Midpoint Temperature (Tm) [amended from Leslie et al., 1995].

1110

\section{Figure 4}

1112 Survival after desiccation of S. meliloti 1021 (WT, grey bar)

1113 and the smc01590: Tn5luxAB mutant (Sce-1, white bar) and the

1114 fold difference in survival of Sce-1 relative to WT (open

1115 circle) at 4,20 and $37^{\circ} \mathrm{C}$.

1116 


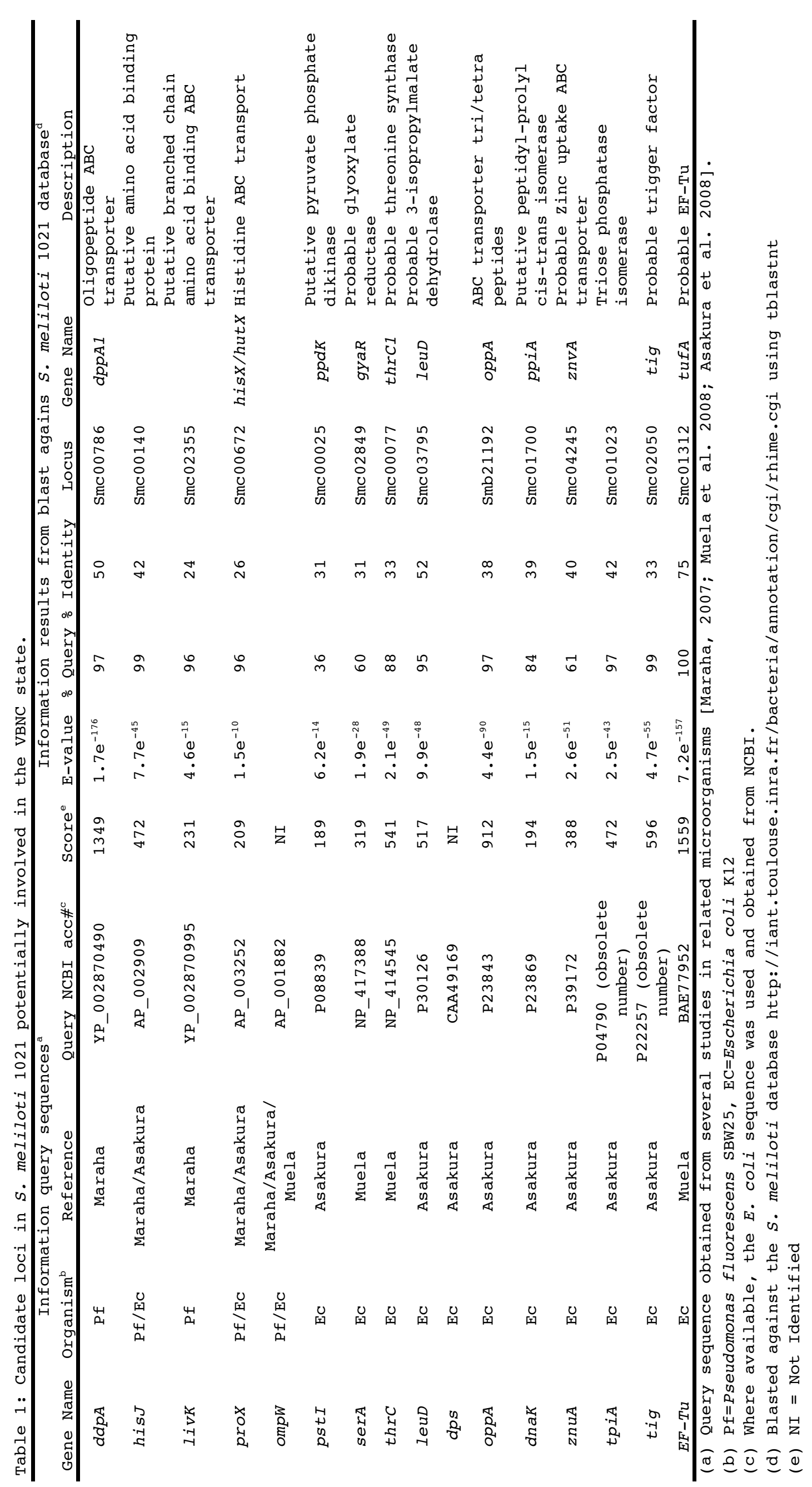




\section{Figure 1}

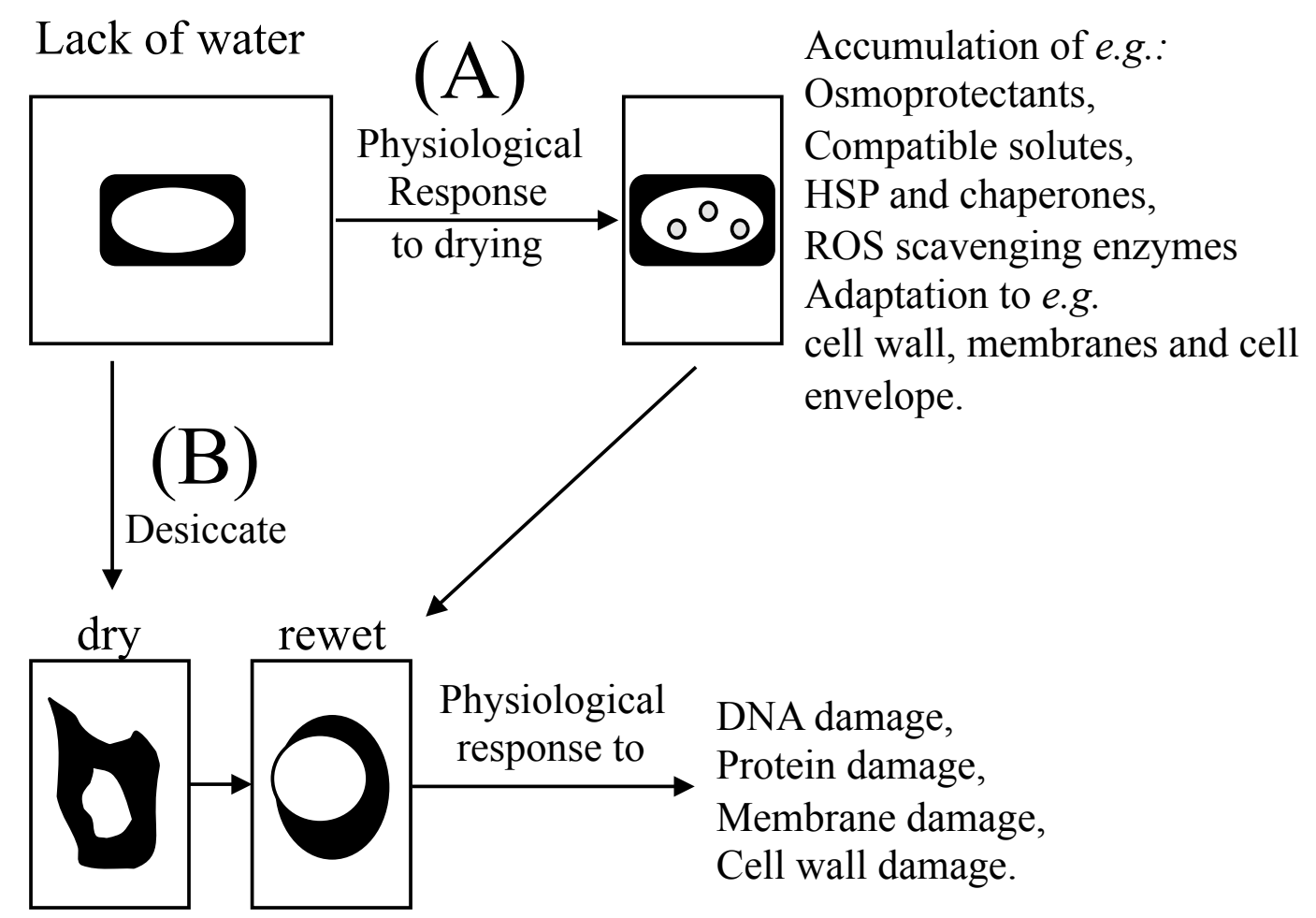


Figure 2

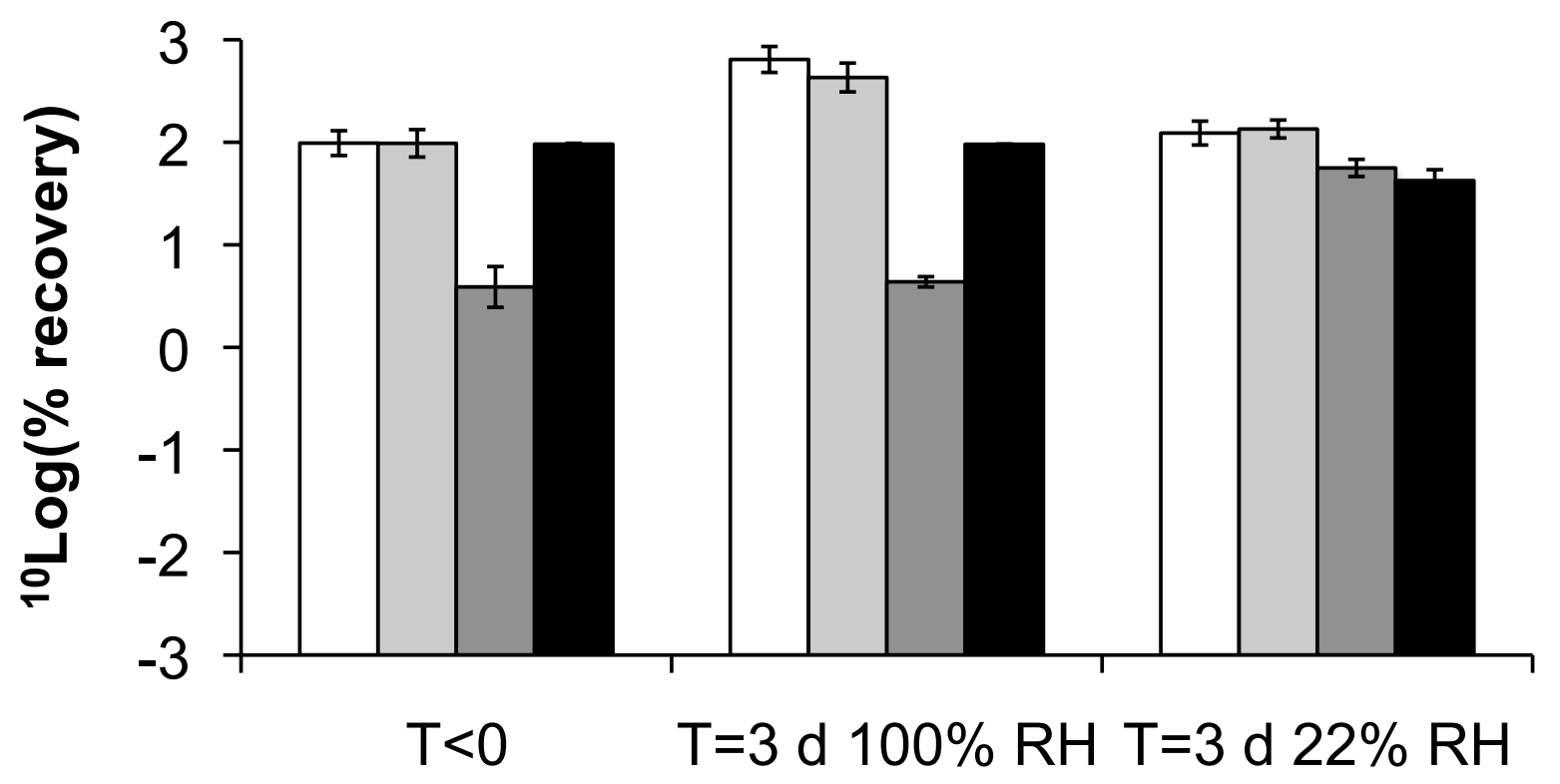

$\square$ cristal violet

$\square \%$ red $\square$ live/dead stain

- \% green 
Figure 3
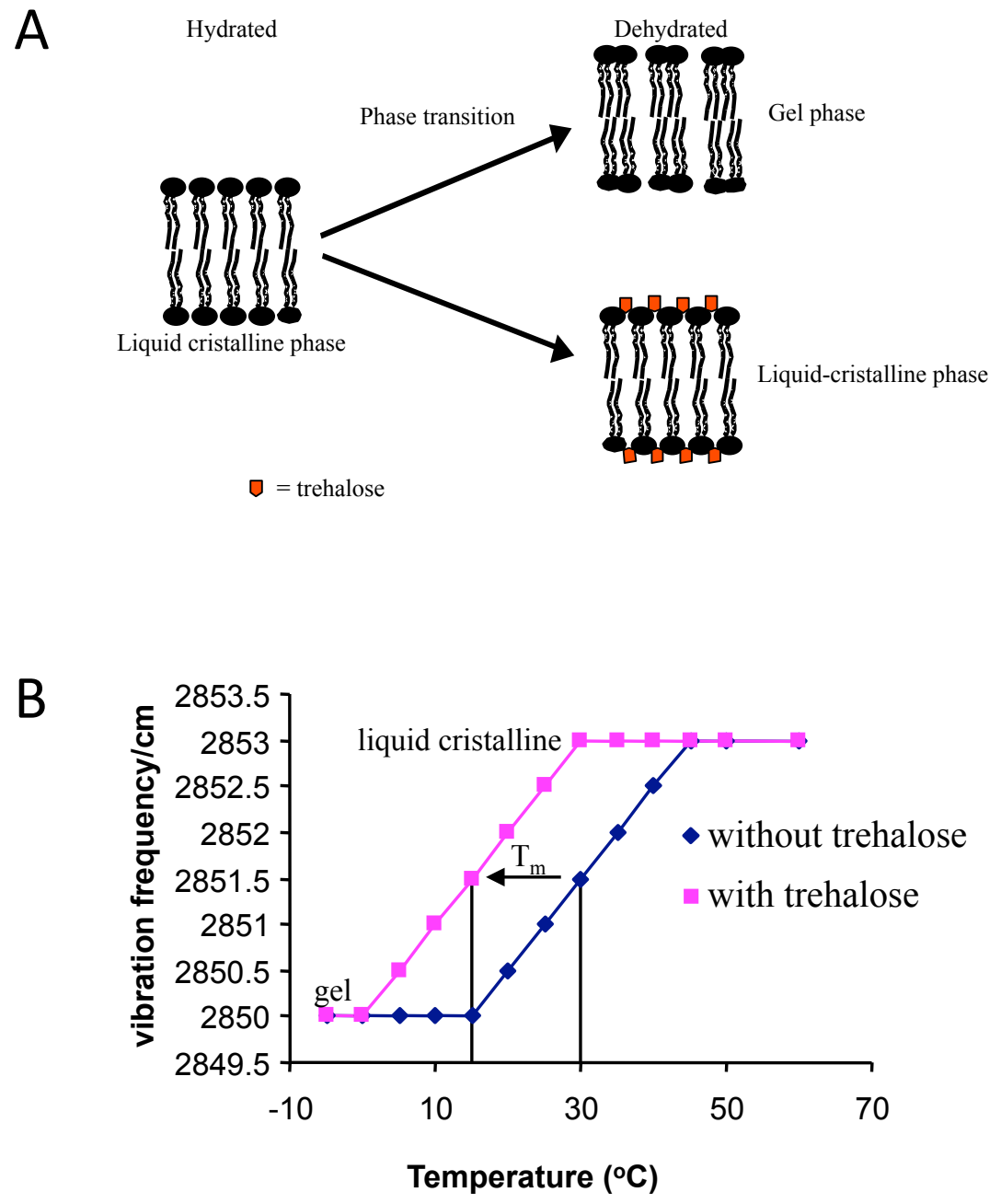
Figure 4

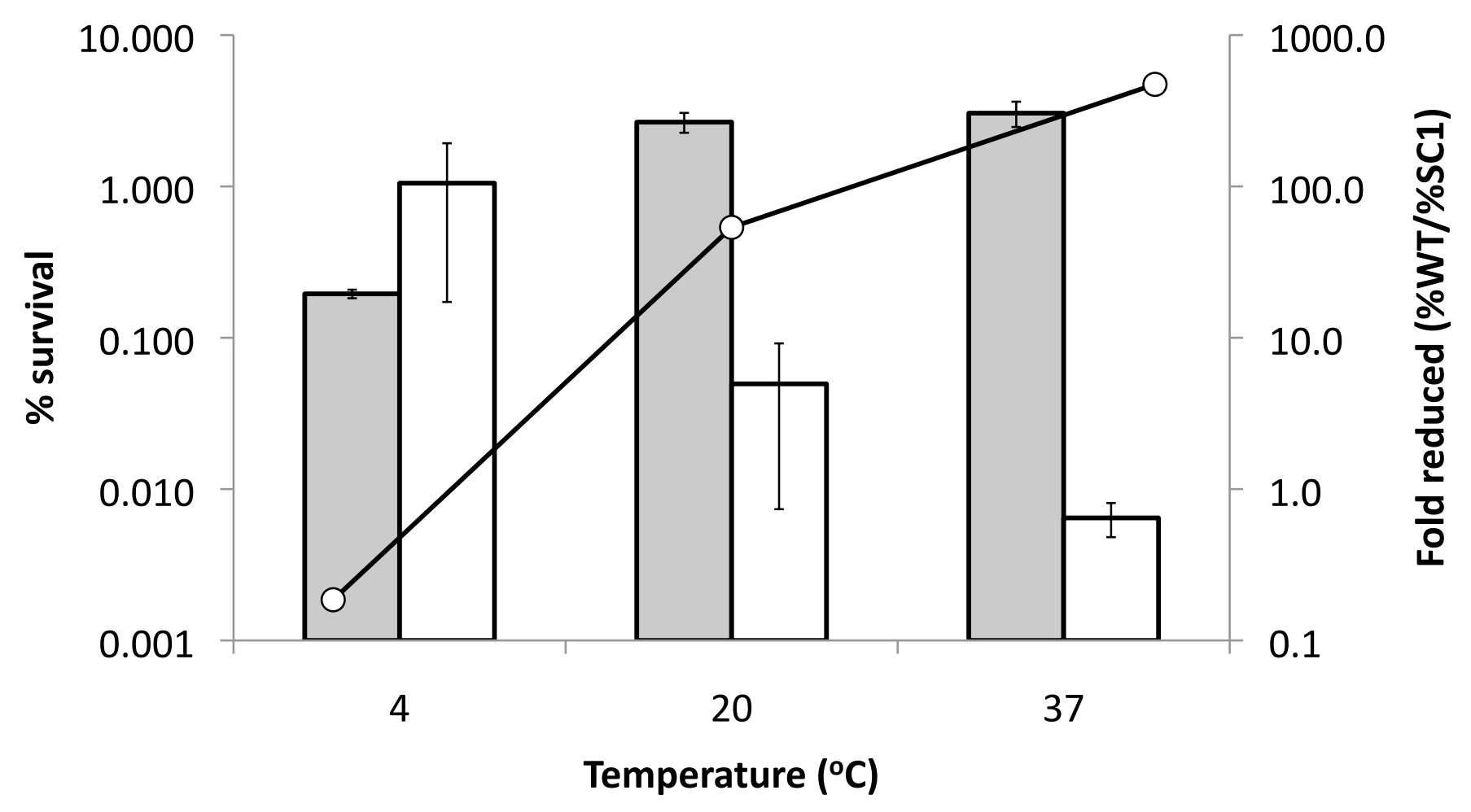

